\title{
Use of corticosteroids in multiple sclerosis by consultant neurologists in the United Kingdom
}

\author{
H L Tremlett, D K Luscombe, C M Wiles
}

\begin{abstract}
Objectives-To survey the use of corticosteroids in multiple sclerosis as recommended by United Kingdom consultant neurologists.
\end{abstract}

Methods-A postal questionnaire covering the use of corticosteroids for acute multiple sclerosis relapse and chronic progressive multiple sclerosis with regard to frequency of use, type of corticosteroid, and dosage regime was sent to all members of the Association of British Neurologists with a United Kingdom address.

Results-Two hundred and twelve United Kingdom consultant neurologists replied to the survey ( $74 \%$ response rate). Eighty six per cent indicated that they prescribed corticosteroids in more than one quarter of acute multiple sclerosis relapses seen. Intravenous methylprednisolone was recommended at some time by $99 \%$ of consultant neurologists, the most popular regime being $1 \mathrm{~g}$ daily for 3 days $(74 \% ; 154$ I $208)$. Over one half $(53 \% ; 109 / 206)$ never recommended a subsequent tapering course of oral corticosteroids; of those that did, $25 \%$ (24/96) recommended a tapering course lasting more than 1 month. Eighty eight per cent (181/206) of prescribers of intravenous methylprednisolone were able to offer the course as a day case on the ward; $7 \%(15 / 206)$ at an outpatient clinic; and 5\% (11/206) at home. Almost three quarters of neurologists recommended oral corticosteroids for some acute relapses, although the most popular response was for occasional use only $(48 \%$; $101 / 212)$. Forty five per cent $(96 / 211)$ at least occasionally recommended steroids for patients with chronic multiple sclerosis not experiencing an acute relapse. Conclusions-Although the vast majority of consultant neurologists would prescribe intravenous methylprednisolone for acute multiple sclerosis relapse at some time, the use of corticosteroids for multiple sclerosis was otherwise variable. There seemed to be little consensus about the use of oral steroids in acute relapse, the prescribing of a tapering course of oral steroids after intravenous methylprednisolone, or the utility of steroids in chronic multiple sclerosis. Variability of prescribing recommendations probably reflects a lack of clear evidence in the face of a wide range of clinical situations, variable access, and timing of access to neurologists in the acute phase of relapse and pressure on neurologists to treat in an otherwise "hopeless" situation. Large multicentred trials are needed to consider these issues.

(F Neurol Neurosurg Psychiatry 1998;65:362-365)

Keywords: multiple sclerosis; corticosteroids; survey

Corticosteroids are widely used for multiple sclerosis. An estimated 8000 to 10000 multiple sclerosis relapses are treated with corticosteroids each year in the United Kingdom. ${ }^{1}$ Prescribing should ideally be evidenced based, although the relevant clinical trials have utilised highly selected patients perhaps not representative of the multiple sclerosis population, insensitive outcome measures, low patient numbers, and sometimes poorly matched patient groups. This survey aimed to determine the recommendations and prescribing habits of corticosteroids for multiple sclerosis by United Kingdom consultant neurologists.

\section{Method}

After piloting a two sided questionnaire, it was sent with a covering letter and freepost return envelope to all full and associate members of the Association of British Neurologists with a United Kingdom address. Most questions were of the closed type, requiring tick box answers to reduce responder burden; a Likert scale was adopted for some questions, response options being: never, occasionally ( $<25 \%$ of cases), sometimes $(25 \%-50 \%$ of cases), frequently ( $>50 \%$ of cases), and always. The questionnaire was anonymous, although responders could add their name and address if they wished to receive a copy of the results on completion of the study. No reminders were sent.

\section{Results}

A total of 548 questionnaires were sent out, 319 were returned, 212 being from consultant neurologists. This represents $74 \%$ of consultants in March 1997 (administrator for the Association of British Neurologists, personal communication), whose responses are detailed below. 
Use of corticosteroids for multiple sclerosis (MS) as recommended by consultant neurologists of the United Kingdom (n (\%))

\begin{tabular}{|c|c|c|c|c|c|c|}
\hline Question (number of valid responders/number of expected responders) & Always & $\begin{array}{l}\text { Frequently } \\
\text { (> 50\% of cases) }\end{array}$ & $\begin{array}{l}\text { Sometimes } \\
\text { (25-50\% of cases) }\end{array}$ & $\begin{array}{l}\text { Occasionally } \\
(<25 \% \text { of cases })\end{array}$ & Never & Missing \\
\hline $\begin{array}{l}\text { (a) Do you recommend/prescribe corticosteroids for acute relapses } \\
\text { of MS? }(n=209 / 212)\end{array}$ & $6(3)$ & $85(41)$ & $89(43)$ & $28(13)$ & $0(0)$ & $3(1)$ \\
\hline $\begin{array}{l}\text { (b) How often do you recommend/prescribe intravenous } \\
\text { methylprednisolone for acute relapses of MS? }(n=212 / 212)\end{array}$ & $26(12)$ & $87(41)$ & $63(30)$ & $33(16)$ & $3(1)$ & $0(0)$ \\
\hline $\begin{array}{l}\text { (c) After a course of iv methylprednisolone, how often do you } \\
\text { recommend/prescribe a tapering course of oral corticosteroids? } \\
(\mathrm{n}=206 / 209)\end{array}$ & $20(10)$ & $17(8)$ & $12(6)$ & $48(23)$ & $109(53)$ & $3(1)$ \\
\hline $\begin{array}{l}\text { (d) How often do you recommend oral corticosteroids as the initial } \\
\text { treatment for MS relapse (instead of iv methylpredisolone?) } \\
(\mathrm{n}=212 / 212)\end{array}$ & $4(2)$ & $12(6)$ & $40(19)$ & $101(48)$ & $54(26)$ & $0(0)$ \\
\hline $\begin{array}{l}\text { (e) Do you use corticosteroids in chronic MS (not including acute } \\
\text { relapse)? }(\mathrm{n}=211 / 212)\end{array}$ & $0(0)$ & $2(1)$ & $9(4)$ & $85(40)$ & $115(55)$ & $1(0.5)$ \\
\hline
\end{tabular}

Note that percentages do not always add up to $100 \%$ for questions with missing responses as the valid percentages have been shown.

CORTICOSTEROIDS FOR ACUTE MULTIPLE

SCLEROSIS RELAPSE

Eighty six per cent of United Kingdom consultant neurologists would prescribe corticosteroids in $25 \%$ or more cases of acute multiple sclerosis relapse. In all, more than $99 \%$ would prescribe corticosteroids for acute multiple sclerosis relapse on some occasions (table (a)). Intravenous methylprednisolone was recommended by $83 \%(176 / 211)$ for the treatment of a quarter or more cases of acute multiple sclerosis relapse (table (b)); 99\% of neurologists would prescribe intravenous methylprednisolone on some occasions. The most popular dosage regime was $1 \mathrm{~g}$ daily for 3 days $(74 \% ; 154 / 208$ of those who recommended intravenous methylprednisolone). The second most popular was $0.5 \mathrm{~g}$ daily for 5 days $(26 \% ; 53 / 208)$. Some recommended either course $(7 \% ; 15 / 208)$.

ORAL CORTICOSTEROID USE AFTER A PULSED COURSE OF INTRAVENOUS METHYLPREDNISOLONE Over half $(53 \% ; 109 / 206)$ would never recommend a tapering course of oral corticosteroids after a pulsed course of intravenous methylprednisolone, whereas 10\% (20/205) always would (table (c)). Oral prednisolone was recommended by $91 \%(87 / 96)$ and dexamethasone by $10 \%$ (10/96), although one consultant would use either. Oral prednisolone starting doses ranged from 20 to $100 \mathrm{mg}$ daily, tapering to zero over 5 to 42 days. Fifty five per cent (53/96) recommended a course tapering for 2 or more weeks, and 25\% (24/96) for a month or more. Of the $10 \%$ (20/206) that always recommended a tapering course of oral prednisolone, $60 \%(12 / 20)$ specified a course tapering for 2 or more weeks and $20 \%(4 / 20)$ for a month or more. Five recommended alternate daily dosing. Oral dexamethasone regimes ranged from 6 to $16 \mathrm{mg}$ daily tapering to zero over 5 to 20 days, the most popular course being a starting dose of $16 \mathrm{mg}$ (the equivalent anti-inflammatory dose of prednisolone being $107 \mathrm{mg}$ ) tapering to zero over 12 to 16 days (4/10).

\section{ADMINISTRATION OF INTRAVENOUS}

METHYLPREDNISOLONE OTHER THAN AS AN INPATIENT

Of those who recommended intravenous methylprednisolone, $88 \%(181 / 206)$ were able to offer the course as a day case on the ward; $7 \%(15 / 206)$ at an outpatient clinic, and 5\%
(11/206) at home. Three consultant neurologists (for whom it was appropriate to answer) did not respond.

ORAL CORTICOSTEROIDS FOR ACUTE MULTIPLE SCLEROSIS RELAPSE

Seventy four per cent (157/212) would recommend oral corticosteroids instead of intravenous methylprednisolone for multiple sclerosis relapse at sometime, although the most popular response was for occasional use $(48 \% ; 101 / 212)$ (table (d)). Sixty six per cent (103/156) recommended oral prednisolone, $23 \%(36 / 156)$ oral methylprednisolone, $14 \%$ (22/156) oral dexamethasone, and two oral prednisone. The most often endorsed oral prednisolone regime was $60 \mathrm{mg}$ daily, tapering to zero over 10 to 28 days (35/156). Other regimes ranged from starting doses of $15 \mathrm{mg}$ to $500 \mathrm{mg}$ tapering to zero over 3 to 56 days. Six per cent (9/156) specified a tapering course lasting more than 1 month. The most popular oral methylprednisolone regimes were $500 \mathrm{mg}$ daily for 5 days $(44 \% ; 16 / 36)$ and $1 \mathrm{~g}$ daily for 3 days (4/36). Dosage regimes of oral dexamethasone ranged from 6 to $16 \mathrm{mg}$ daily for 5 to 21 days. Some recommended either of the 2 types of corticosteroid. In all 13 did not specify a dose, three of whom wrote "variable". One did not respond to the whole question.

CORTICOSTEROIDS FOR CHRONIC MULTIPLE SCLEROSIS (NOT INCLUDING ACUTE RELAPSE) The majority $(55 \% ; 115 / 211)$ said that they never used corticosteroids for patients with chronic progressive multiple sclerosis who were not in acute relapse, but 45\% (96/211) would do so at times and 5\% (11) would do so in more than a quarter of cases (table (e)). Intravenous methylprednisolone was the most popular drug for chronic progressive multiple sclerosis $(76 \% ; 70 / 92$ of responders), the most often used regime being $1 \mathrm{~g}$ daily for 3 days (30 out of 65 who specified a dose). A course of oral prednisolone was the second most popular option $(34 \% ; 31 / 92)$. Courses varied greatly, ranging from starting doses of 15 to $60 \mathrm{mg}$ tapering to zero over 12 to 84 or more days. Two consultants occasionally used long term oral prednisolone (more than 3 months) and two used alternate day dosing. Other corticosteroids recommended included dexamethasone (four) oral methylprednisolone (two), and ACTH (one). Five neurologists for whom it was applicable to answer the question did not 
do so, a further $28 \%$ (26/92) did not specify a dosage regime, although some recommended more than one course.

\section{Discussion}

Eighty six per cent of United Kingdom consultant neurologists would prescribe corticosteroids in a quarter or more cases of acute multiple sclerosis relapse; more than $99 \%$ would prescribe corticosteroids for acute multiple sclerosis relapse on some occasions. Therefore there was consensus that steroids should be prescribed for some relapses of multiple sclerosis, intravenous methylprednisolone being recommended in a fair proportion. No clear consensus was evident as to the type, duration, and dosage of corticosteroids or in their use for chronic multiple sclerosis. Evidence from randomised clinical trials confirms that corticosteroids are superior to placebo in accelerating recovery from relapses. The first trial in the 1960s found ACTH (not commercially available in the United Kingdom any more due to its variable and unpredictable therapeutic response) to be superior to placebo, ${ }^{2}$ in two later trials intravenous methylprednisolone was found to be comparable or superior to ACTH. ${ }^{3}{ }^{4}$ Intravenous methylprednisolone $(15 \mathrm{mg} / \mathrm{kg} /$ daily tapering to zero over 15 days $(n=23),{ }^{5}$ or $500 \mathrm{mg}$ daily for 5 days $(\mathrm{n}=50),{ }^{6}$ or $1 \mathrm{~g}$ daily for 5 days $(\mathrm{n}=35)^{7}$ has been shown to be more effective than placebo. High dose intravenous methylprednisolone ( $5750 \mathrm{mg}$ total over 14 days) has been shown to be comparable with intravenous dexamethasone $(n=31)^{8} \quad(78 \mathrm{mg}$ over 14 days; total equivalent anti-inflammatory dose being 390 mg methylprednisolone).

Patients in clinical trials, however, may not be representative of the population seen by neurologists in clinical practice. Reasons probably include variable access of patients with relapsing multiple sclerosis to specialist neurology services: some being seen at the height of relapse, others when the relapse has resolved or is obviously improving, and an unknown proportion of less severe episodes either being assessed by the general practitioner or not at all.

There is little evidence to advocate corticosteroids in chronic progressive multiple sclerosis, ${ }^{679}$ although $45 \%$ of neurologists would do so at least occasionally, perhaps unconvinced by evidence based on small numbers. Alternatively there may be pressure to offer "something" in an otherwise "hopeless" situation.

Ten per cent (20/206) of neurologists always recommended a tapering course of oral corticosteroids after intravenous methylprednisolone, with 25\% (24/96) advocating a course lasting a month or more. Evidence for or against tapering oral corticosteroids after intravenous methylprednisolone is scant: increased side effects have been found without measurable beneficial effects. ${ }^{5}$ Furthermore, the hypothalamic-pituitary-adrenal axis recovers sufficiently after short term high dose intravenous methylprednisolone such that oral replacement therapy is not required for this reason. ${ }^{10}$ Thus a short tapering course of oral corticosteroids seems justified only for a few patients clearly shown to relapse when a pulsed course of intravenous methylprednisolone is stopped.

Data from two recent clinical trials have suggested equivalence between oral and intravenous corticosteroids, ${ }^{11}$ and although almost three quarters of neurologists recommended oral corticosteroids instead of intravenous methylprednisolone for acute multiple sclerosis relapse at sometime, only a minority $(8 \% ; 16 / 212)$ often or always did so. The most popular oral corticosteroid was prednisolone $(66 \% ; 103 / 156)$ starting at 60 $\mathrm{mg}$, tapering to zero over 20 to 28 days (22\%; $35 / 156)$, the regime recommended in one recent trial. ${ }^{1}$ Fear was expressed that the prescribing of oral rather than intravenous corticosteroids for acute multiple sclerosis relapse would lead to chronic courses of corticosteroids ${ }^{12}$; however, this was not substantiated by the results seen here. Only $6 \%$ (9/156) of respondents recommended oral corticosteroids for more than one month, although it is not known whether these recommendations are adhered to in practice, especially once the patient is under general practitioner supervision. Corticosteroids given orally have several advantages over those given intravenously-namely, reduced nursing and doctor time, reduced risk of infection (associated with intravenous administration), reduced necessity to admit to hospital, and an estimated cost saving of $£ 472000$ per year in the United Kingdom (if all multiple sclerosis relapses were treated with oral prednisolone instead of intravenous methylprednisolone). ${ }^{13}$ However, most neurologists remained unconvinced that oral instead of intravenous corticosteroids should be routinely prescribed; a larger randomised multicentre trial may clarify previous findings and help to rationalise practice.

The study was carried out as part of a $\mathrm{PhD}$ supported by the Welsh School of Pharmacy. We thank Claire Grout for help with piloting the questionnaire and Susan Tann, administrator of the Association of British Neurologists for her help and cooperation.

1 Barnes D, Hughes RAC, Morris RW, et al. Randomised trial of oral and intravenous methylprednisolone in acute relapses of multiple sclerosis. Lancet 1997;349:902-6.

2 Rose AS, Kuzma JW, Kurtzke JF, et al. Co-operative study in the evaluation of therapy in multiple sclerosis: ACTH vs placebo. Neurology 1970;6:1-59.

3 Thompson AJ, Kennard C, Swash M, et al. Relative efficacy of iv methylprednisolone and ACTH in the treatment of of iv methylprednisolone and ACTH in the treatment of 71 .

4 Barnes MP, Bateman DE, Clelan PG, et al. Intravenous methylprednisolone for multiple sclerosis in relapse. $f \mathrm{Neu}$ rol Neurosurg Psychiatry 1985;48:157-9.

5 Durelli L, Cocito D, Riccio A, et al. High-dose iv methylprednisolone in the treatment of multiple sclerosis. Neurology 1986;36:238-43.

6 Milligan NM, Newcombe R, Compston DAS. A double blind controlled trial of high dose methylprednisolone in patients with multiple sclerosis. F Neurol Neurosurg Psychiatry 1987;50:511-6.

7 Cazzato G, Mesiano T, Antonallo R, et al. Double-blind, placebo-controlled, randomized, crossover trial of highdose methylprednisolone in patients with chronic progres-

8 La Mantia L, Eoli M, Milanese C, et al. Double-blind trial of dexamethasone versus methylprednisolone in multiple sclerosis acute relapses. European Neurology 1994;34:199203. 
9 Millar JHD, Vas CJ, Noronha MJ, et al. Long-term treatment of multiple sclerosis with corticotrophin. Lancet

10 Wenning GK, Wietholter H, Schnauder G, et al. Recovery of the hypothalamic-pituitary-adrenal axis from suppression by short-term, high-dose intravenous prednisolone therapy in patients with MS. Acta Neurol Scand 1994;89:270-3.

11 Alam SM, Kyriakides T, Lawden M, et al. Methylpred- nisolone in multiple sclerosis: a comparison of oral with iv therapy at equivalent high dose. $\mathcal{f}$ Neurol Neurosurg (1993;56:1219-20.

12 Barkhof F, Polman C. Oral or intravenous methylprednisolone for acute relapse of multiple sclerosis. Lancet 1997;349:893-4

13 Tremlett HL. Oral versus intravenous corticosteroids in acute relapses of multiple sclerosis. Lancet 1997;340:1696-7.

\section{NEUROLOGICAL PICTURE}

\section{Thoracocervicofacial purpura as the single manifestation of epileptic seizure}
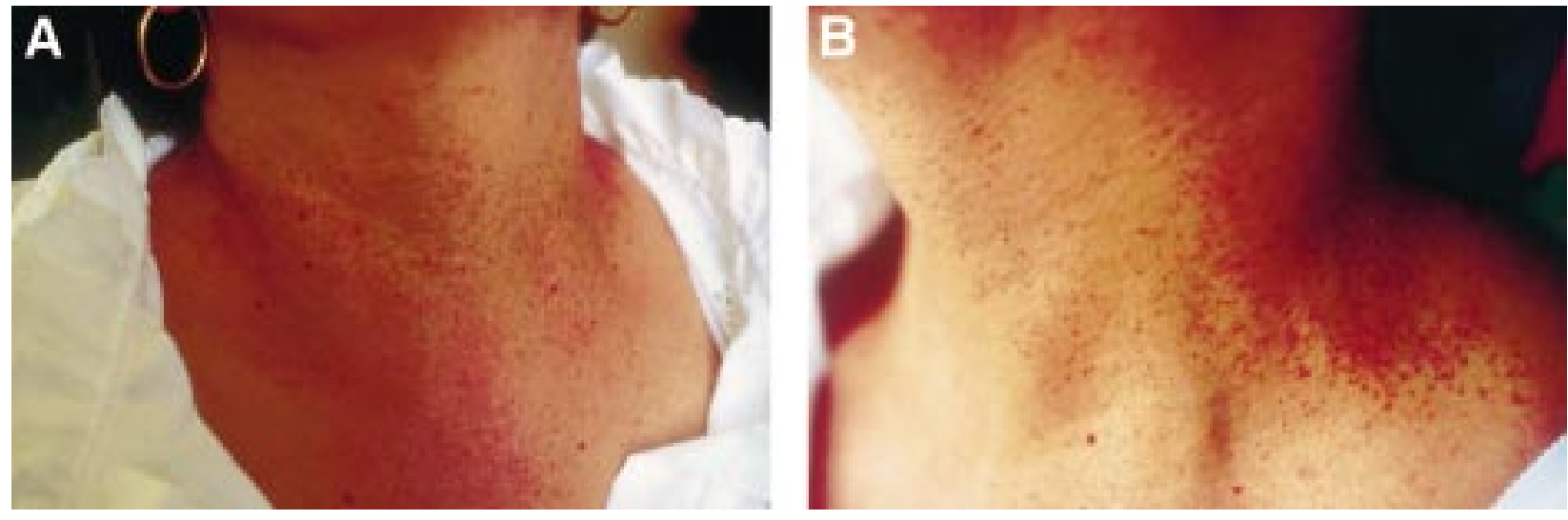

Petechial haemorrhage of the thoracocervicofacial area has been described as an unusual consequence of epileptic seizure. ${ }^{1-4}$ Here we report a case of thoracocervicofacial purpura as the unique manifestation of epileptic seizure.

A 44 year old woman who underwent ovariectomy due to bilateral ovarian cysts at the age of 29 followed by hormone replacement therapy for several years, was admitted to hospital after a generalised grand mal seizure. The patient had no history of epilepsy. Neurological examination on admission was negative; however, purpura of the thoracocervicofacial region was seen (figure). Routine blood chemistry (platelet count on FBC) and chest radiography were normal. Cranial CT and MRI did not show any parenchymal pathology. An EEG trace was within normal limits.

Purpura was described in association with generalised seizures by Bychowski. ${ }^{1}$ Guillaume proposed that this type of purpura was of mechanical origin ${ }^{5}$, due to intense contraction of the chest and abdominal muscles with the glottis closed during the tonic-clonic phase, as in the Valsalva manoeuvre.

PIETRO RUBEGNI MICHELE FIMIANI GIOVAMBATTISTA DE ALOE LUCIO ANDREASSI Department of Dermatology of University of Siena, Italy

MARIO RUBEGNI Division of Geriatrics, Azienda Ospedaliera, Siena, Italy

Correspondence to: Dr Pietro Rubegni, Istituto di Scienze Dermatologica, Università degli Studi di Siena, Policlinico "Le Scotte", Viale Bracci, 53100 Siena, Italy. Telephone 0039577 585420; fax 003957744238.

1 Bychowsky Z. Zur kasuistik der stauungsblutungen wahrend eines epileptischen Anfalls. Zentralbl Innere Medizin 1903;14:346-7.

2 Friebourg-Blanc A. Les hèmorragies rèvèlatrices de l'epilepsie. Science Mèd Prat 1936;1:136-0.

3 Bertrand F, Le Pileur P, Fournier JP, et al. De l'intèrèt de recherche un purpura cervico-facial et thoracique dans les suites d'une perte de connaissance. La presse Médicale 1993;22:1794.

4 Defevre L, Fillebeen C, Ketelers JY, et al. Purpura rèvèlateur d'une crise convulsive. La Presse Médicale 1993;22:49.

5 Guillaume AC. A propos del phénomènes vaso-moteurs dans l'attaque d'èpilepsie. Compte rendu hebdomadaire des sèances et mèmories de la Sociètè de Biologie 1922; 15:516-7. 